\title{
A Incompatibilidade da Substituição Tributária do ICMS com a Opção pelo Simples Nacional
}

\author{
Fábio Pugliesi ${ }^{1}$
}

Resumo: Este artigo estuda a compatibilidade das disposições da Constituição da República Federativa do Brasil, relativas à substituição tributária progressiva e ao regime jurídico de recolhimento simplificado e único em que se inclui o imposto sobre operações relacionadas à circulação de mercadorias e sobre prestações de serviços de transporte interestadual, intermunicipal e de comunicação (ICMS). Analisa-se a disciplina da apuração pelo regime simplificado instituído pela Lei Complementar n. 123, de 14 de dezembro de 2006, denominado Simples Nacional, os meios de controle da arrecadação e da fiscalização do Simples Nacional. Expõe o histórico, competência tributária, hipótese de incidência e o princípio da não cumulatividade do ICMS. Expõe as formas de substituição tributárias admitidas, em particular a substituição tributária progressiva, e o acórdão do Supremo Tribunal Federal na Ação Direta de Inconstitucionalidade n. 1.851-4. Por fim, considera que é incompatível o exercício da substituição tributária com o Simples Nacional.

Palavras-chave: Substituição Tributária. Simples Nacional. ICMS.

\begin{abstract}
This article examines the compatibility of the provisions of the Constitution of the Federative Republic of Brazil concerning the replacement tax and progressive legal framework for simplified and unique collection which includes the tax on circulation of merchandises and services on the interstate transportation and communication - ICMS. Analyze the subject of scrutiny by the simplified scheme introduced by Complementary Law 123 of 14 December 2006, called Simple National, means of control, collection and monitoring of National Simple. Exposes the historical of power to tax and the principle of non-cumulative ICMS. Exposes the replacement tax forms allowed, in particular the progressive tax replacement, and the Supreme Court ruling in the Federal Direct Action of Unconstitutionality n. 1851-4. Finally, it considers that the exercise is of replacing incompatible with the Single National tax.
\end{abstract}

Key words: Tax Substitution. National Simple. ICMS.

1 Doutor em Direito pela Universidade Federal de Santa Catarina. Mestre em Direito pela Universidade de São Paulo. Especialista em Administração pela EAESP-FGV. Professor adjunto da Escola Superior de Administração e Gerência da Universidade do Estado de Santa Catarina, Centro Universitário para o Desenvolvimento do Alto Vale do Itajaí e Faculdade Estácio de Sá Santa Catarina.E-mail: fabio_pugliesi@hotmail.com.

Recebido em: 26/02/2012.

Revisado em: 30/04/2012.

Aprovado em: 16/05/2012. 


\section{Introdução}

O Regime Especial Unificado de Arrecadação de Tributos e Contribuições, devidos pelas Microempresas e Empresas de Pequeno Porte - Simples Nacional e instituído pela Lei Complementar n. 123, de 14 de dezembro de 2006, veicula uma disciplina de apuração de tributos que busca conferir tratamento diferenciado e favorecido para as microempresas (ME) e para as empresas de pequeno porte (EPP) e é determinado pela Constituição da República Federativa do Brasil (CRFB).

A Emenda Constitucional (EC) n. 3, de 17 de março de 1993, introduziu, na CRFB, a possibilidade da lei atribuir ao sujeito passivo de obrigação tributária a condição de responsável pelo pagamento de imposto ou contribuição, cujo fato gerador deva ocorrer posteriormente, denominado de substituição tributária progressiva ou "para frente".

Outros tributos podem ser objeto de substituição tributária progressiva, mas se analisará a compatibilidade do regime jurídico da substituição tributária do imposto sobre operações relativas à circulação de mercadorias e sobre prestações de serviços de transporte interestadual, intermunicipal e de comunicação (ICMS), de competência dos Estados, nas aquisições de mercadorias destinadas à industrialização e revenda por empresas optantes pelo Simples Nacional.

A aplicação da substituição tributária, nos fornecimentos para ME e EPP, para as optantes do Simples Nacional tem grande relevância, pois tem se verificado que os Estados têm fixado critérios que resultam em preços presumidos de venda superiores aos verificados no mercado, o que tem dificultado e até inviabilizado a atividade das MEs e das EPPs.

O conteúdo deste artigo encontra-se organizado da seguinte forma para analisar a compatibilidade da substituição tributária do ICMS com o Simples Nacional: primeiramente, descrevem-se a forma de apuração, os meios de controle da arrecadação e fiscalização do Simples Nacional. Em seguida, considera-se a disciplina do ICMS, seu histórico e, em especial, o princípio da não cumulatividade. Posteriormente, analisa-se o instituto da substituição tributária, em especial a substituição tributária progressiva, prevista no parágrafo 7 , do artigo 150 da CRFB, acrescentada pela EC 
n. 3/93, em vista do acórdão do Supremo Tribunal Federal na Ação Direta de Inconstitucionalidade n. 1851-4, bem como a compatibilidade desse acórdão com o regime de apuração do Simples Nacional, agravado por ser anterior à EC n. 42/03.

Por fim, estuda-se a disciplina da relação da "opção" pelo regime de apuração simplificado, previsto no inciso III, alínea "d" do artigo 146 da CRFB, acrescentado pela EC n. 42/03, e o regime da substituição tributária progressiva.

\section{Simples Nacional}

A CRFB, no inciso IX do artigo 170, elenca, entre os princípios que devem orientar a ordem econômica, o tratamento favorecido para as empresas de pequeno porte sob as leis brasileiras e que tenham sua sede e administração no País. Segundo Eros Roberto Grau, trata-se de um princípio constitucional impositivo ${ }^{2}$, segundo a classificação de José Joaquim Gomes Canotilho, autorizando a reivindicação, por tais empresas, pela realização de políticas públicas. (GRAU, 2007, p. 253)

No artigo 179 da CRFB, tal princípio impositivo segue reafirmado ao se obrigar que os Estados, o Distrito Federal e os Municípios dispensarão às microempresas e às empresas de pequeno porte, assim definidas em lei, tratamento jurídico diferenciado, visando incentivá-las pela simplificação no cumprimento de suas obrigações administrativas, tributárias, previdenciárias e creditícias “[...] ou pela eliminação ou redução destas por meio da lei".

Infere-se que a expressão "[...] eliminação ou redução destas por meio da lei $[. .$.$] " tem o caráter de impor que a lei venha ampliar, ainda$ mais, a simplificação da observância da lei, jamais dificultar.

Para garantir ainda mais essa imposição constitucional, a par das limitações constitucionais ao poder de tributar que será objeto de análise na

2 Os princípios constitucionais impositivos subsumem-se todos os princípios que, no âmbito da constituição dirigente, impõem aos órgãos do Estado, sobretudo ao legislador, a realização de fins e a execução de tarefas. (CANOTILHO, 1991, p. 179) 
medida de sua relação com tema, a CRFB veio autorizar, por intermédio da Emenda à Constituição n. 42, de 19 de dezembro de 2003, a instituição de um regime único de arrecadação dos impostos e das contribuições da União, dos Estados, do Distrito Federal e dos Municípios, conforme o disposto no parágrafo único do artigo 146, segundo o disposto na Emenda à Constituição n. 42, de 19 de dezembro de 2003.

A Lei Complementar n. 123, de 14 de dezembro de 2006, com as modificações introduzidas pela Lei Complementar n. 127, de 14 de agosto de 2007 e a Lei Complementar n. 139, de 10 de novembro de 2011, doravante denominada "Simples Nacional", a par de instituir o regime de arrecadação já aludido, define como microempresas ou empresas de pequeno porte a sociedade empresária, a sociedade simples e o empresário, registrados no Registro de Empresas Mercantis ou no Registro Civil de Pessoas Jurídicas, buscando simplificar as formalidades de constituição, funcionamento e extinção da atividade empresarial com o objetivo de reduzir os controles e as formalidades que dificultam a atividade empresarial do Brasil.

A fim de enquadrar-se como tal, o empresário, a pessoa jurídica ou a pessoa a ela equiparada para fins de tributação, em particular do imposto de renda, deve auferir, em cada ano-calendário, receita bruta igual ou inferior a $\mathrm{R} \$ 360.000,00$ (trezentos de sessenta mil reais), a fim de ser considerada microempresa para os fins dessa lei; e até R\$3.600.000,00 (três milhões e seiscentos mil reais) para ser considerada empresa de pequeno porte.

A lei prevê exceções decorrentes dos sócios e da atividade, cuja análise se abstrai por extrapolar os limites do presente artigo. Pode-se reafirmar, porém, que as MEs e as EPPs devem ter a forma de empresas individuais, sociedades limitadas ou empresa individual de responsabilidade limitada, nas duas últimas formadas exclusivamente por pessoas naturais.

Institui, também, a Lei Complementar n. 123/06, o Regime Especial Unificado de Arrecadação de Tributos e Contribuições devidos pelas Microempresas e Empresas de Pequeno Porte a que denomina Simples Nacional, segundo o autorizado pela Constituição Federal. 
Em virtude do enquadramento no Simples Nacional, o contribuinte pode recolher, por meio de documento único (curioso que a lei destaca isso explicitamente ${ }^{3}$ ) os seguintes tributos: Imposto sobre a Renda da Pessoa Jurídica (IRPJ); Imposto sobre Produtos Industrializados (IPI), não incluso para tal fim o incidente na importação; a Contribuição Social sobre o Lucro Líquido (CSLL); a Contribuição para o Financiamento da Seguridade Social (COFINS); a Contribuição para o PIS/Pasep; a Contribuição para a Seguridade Social sobre a folha de salários e demais rendimentos pagos a pessoa física que lhe preste serviço, neste caso, observadas as exceções constantes no parágrafo 5-B do artigo 18 da Lei Complementar 123/06 (BRASIL, 2006) lativas à Circulação de Mercadorias e Sobre Prestações de Serviços de Transporte Interestadual e Intermunicipal e de Comunicação (ICMS); bem como o Imposto sobre Serviços de Qualquer Natureza (ISS). Caso o ICMS seja retido a título de substituição tributária progressiva, não é devido o ICMS pelo regime do Simples Nacional, o que não observa o princípio da capacidade contributiva, como se verá.

3 Art. 13 - O Simples Nacional implica o recolhimento mensal, mediante documento único de arrecadação, dos seguintes impostos e contribuições.

4 XIII - construção de imóveis e obras de engenharia em geral, inclusive sob a forma de subempreitada;

$\mathrm{XIV}$ - transporte municipal de passageiros;

$\mathrm{XV}$ - empresas montadoras de estandes para feiras;

XVI - escolas livres, de línguas estrangeiras, artes, cursos técnicos e gerenciais;

XVII - produção cultural e artística;

XVIII - produção cinematográfica e de artes cênicas;

XIX - cumulativamente administração e locação de imóveis de terceiros;

$\mathrm{XX}$ - academias de dança, de capoeira, de ioga e de artes marciais;

XXI - academias de atividades físicas, desportivas, de natação e escolas de esportes;

XXII - (VETADO);

XXIII - elaboração de programas de computadores, inclusive jogos eletrônicos, desde que desenvolvidos em estabelecimento do optante;

XXIV - licenciamento ou cessão de direito de uso de programas de computação;

XXV - planejamento, confecção, manutenção e atualização de páginas eletrônicas, desde que realizados em estabelecimento do optante;

XXVI - escritórios de serviços contábeis;

XXVII - serviço de vigilância, limpeza ou conservação [...] 
Em contrapartida, as microempresas e as empresas de pequeno porte optantes pelo Simples Nacional devem renunciar ao crédito do ICMS, não se lhes aplicando, consequentemente, o fundamento constitucional da não cumulatividade, em que se autoriza a compensação do tributo com o cobrado nas operações anteriores, segundo o disposto no inciso I, parágrafo $2^{\circ}$, do artigo 155 da CF. Ademais, passa a ser vedada a utilização ou destinação de qualquer valor a título de incentivo físcal.

As ações de execução fiscal serão ajuizadas pela União após a inscrição no seu cadastro da dívida ativa. Dessa forma, na hipótese do contribuinte sujeito ao Simples Nacional ter declarado o tributo e não pagá-lo, lavrar-se-á termo de dívida ativa, a fim de se proceder à execução do crédito tributário.

Por sua vez, pode a União, representada pela Procuradoria-Geral da Fazenda Nacional, celebrar convênio com os demais entes federativos, delegando a cobrança judicial dos tributos estaduais e municipais integrantes do Simples Nacional.

O Simples Nacional facilita a apuração de tributos, o que não deve ser negligenciado devido à complexidade da legislação de cada um dos tributos por ele englobados.

As obrigações exigidas na apuração isolada dos tributos pela empresa implicam grandes despesas, sendo que o Brasil é o país, entre as 183 economias pesquisadas pelo Banco Mundial no relatório "Doing Business", em que uma empresa média com 60 empregados (THE WORLD BANK, 2010) gasta mais tempo para apurar e recolher tributos (2.600 horas por ano), seguido da Bolívia (1.000 horas por ano). (THE WORLD BANK, 2010)

Assim, a pequena empresa pode até aceitar um aumento de sua carga tributária para se livrar da complexidade de apuração dos tributos e de suas obrigações tributárias acessórias, o que acarreta a apuração isolada de tributos, além do maior controle do pagamento tributos, em relação ao recolhimento separado de tributos. (PUGLIESI, PIRES, 2008)

Diante desse cenário, considerar-se-á a seguir a sistemática do ICMS, seu histórico e o princípio da não cumulatividade. 


\section{ICMS e a não Cumulatividade}

O ICMS, instituído pela CRFB, foi precedido pelo Imposto sobre Circulação de Mercadorias (ICM), instituído pela EC n. 18/65 na vigência da Constituição de 1946, tendo este substituído o Imposto sobre Vendas e Consignações estadual. Enquanto este só incidia sobre determinados negócios jurídicos e cumulativamente, aquele tem incidência genérica, não se vinculando aos negócios jurídicos.

Em 1967 passou a vigorar uma Constituição, preparada pelo regime militar, que praticamente obrigou o Congresso a aprová-la (BALTHAZAR, 2007, p. 159), tendo esta mantido a competência do ICM, adotada pela EC n. 18/65.

Por sua vez, a EC n. 1/69 para a Constituição de 1967 alterou radicalmente o texto da Constituição de 1967, a tal ponto que se considera ter surgido uma nova Constituição, mas a competência do ICM permaneceu inalterada.

O artigo 155 da CRFB, instituída em 1988, atribui aos Estados e ao Distrito Federal a competência para instituir impostos sobre: a transmissão causa mortis e doação de quaisquer bens ou direitos; propriedade de veículos automotores; e, por fim, o objeto deste trabalho, operações relativas à circulação de mercadorias e sobre prestações de serviços de transporte interestadual e intermunicipal e de comunicação, ainda que as operações e as prestações se iniciem no exterior.

A Lei Complementar n. 87, de 13 de setembro de 1996, acolheu a perspectiva que a operação é qualquer ato voluntário, disciplinado no Direito Privado, que impulsione mercadorias da fonte de produção até o consumo, tenha ou não o caráter, por parte do agente, de criar, modificar e extinguir direitos. (COSTA, 1978)

José Eduardo Soares de Melo, com base em Paulo de Barros Carva1ho, entende que mercadoria corresponde àqueles bens submetidos à mercancia pelo produtor; pelo industrial; pelo comerciante; pelo importador ou pelo exportador, "[...] prática esta regida pelos cânones do Direito Comercial.” (MELO, 2004, p. 38) 
Interessante o entendimento de Marco Aurélio Greco que descreve da seguinte forma os três mecanismos para abarcar a realidade que a hipótese de incidência quer alcançar: a "enumeração dos casos", como se faz na lista de serviços do ISS; "efeitos padrão", relevância do aumento patrimonial para tributar como estabelece o imposto de renda; e, por fim, "categorias de fatos", por exemplo, ao invés de listar os atos jurídicos, utiliza-se

[...] o conceito de atos translativos de propriedade e, portanto, seja qual for a inventividade humana se o ato corresponder a um ato translativo de propriedade estará inserido na previsão. (GRECO, 2004, p. 38).

O regime jurídico do ICMS insere-se entre as hipóteses de incidência que utilizam "categorias de fatos" desde que substituiu o imposto sobre e vendas e consignações, como já aludido.

Assinale-se que o artigo 155, parágrafo $2^{\circ}$, inciso IX, alínea "a" da CRFB estabelece que o ICMS incide sobre a entrada de bem ou mercadoria importados do exterior por pessoa física ou jurídica, todavia não pode ser objeto de crédito pelas microempresas (ME) e as empresas de pequeno porte-EPP, em vista do disposto no artigo 23 da Lei Complementar n. 123, de 14 de dezembro de 2006 - Estatuto Nacional da ME e EPP, que não vai ser objeto de análise, ante os limites deste trabalho.

Assim mesmo deve ser considerada a advertência de Láudio Camargo Fabretti que o preço das mercadorias ou produtos industrializados das MEs e das EPPs fica mais caro do que suas concorrentes não enquadradas no Simples Nacional. (FABRETTI, 2007, p. 73)

Assim, aludida a não cumulatividade, passa-se ao seu exame. $\mathrm{O}$ artigo 155 , parágrafo $2^{\circ}$, inciso I da CRFB dispõe que ele “[...] será não cumulativo, compensando-se o que for devido em cada operação relativa à circulação de mercadorias ou prestação de serviços com o montante cobrado nas anteriores pelo mesmo ou outro Estado ou pelo Distrito Federal". Verifica-se, em linhas gerais, que os valores cobrados devem gerar um crédito a ser abatido contra o imposto devido na etapa subsequente. 
Concebeu-se o ICMS nos moldes do Imposto sobre Valor Agregado (IVA), pensado e desenvolvido na França.

Em estudo que recupera antecedentes do imposto, Balthazar alerta, porém, que o mecanismo de deduções já existia anteriormente ao IVA francês. Constata que, baseados na doutrina norte-americana e alemã, apresentaram-se projetos, a exemplo dos surgidos na Turquia, Grécia e Argentina, que possuíam como base de cálculo a margem bruta ou valor agregado da empresa, não atingindo os produtos ou os serviços fabricados, chamado de "base sobre base" (BALTHAZAR, 2008). Diferente do "imposto sobre imposto", portanto, em que se deduz o imposto incidente na operação interior.

O regime de compensação do ICMS imposto experimentou a seguinte evolução no Brasil: o Decreto-Lei n. 406, de 31 de dezembro de 1968, editado na vigência da Constituição de 1967, autorizava o abatimento do montante de matéria-prima ou material secundário, utilizados na fabricação e na embalagem dos produtos, além de, obviamente, as mercadorias destinadas à revenda nas operações anteriores pelo mesmo Estado em que ocorre a operação ou outro Estado ou o próprio Distrito Federal.

Esse Decreto-lei disciplinava também os fatos geradores, as bases de cálculo e os contribuintes do Imposto sobre Serviços de Qualquer Natureza (ISS) de competência dos Municípios, além de estabelecer uma lista de serviços sujeitos ao imposto que deve ser cumprida pelos Municípios no exercício da competência do ISS.

Observa-se que continua a fazer parte da CRFB em vigor o ISS, sendo que os serviços sujeitos à sua tributação encontram-se arrolados em uma lista constante na Lei Complementar n. 116, de 31 de julho de 2003, que geram crédito do ICMS a exemplo do que já ocorria no Decreto-Lei n. $406 / 67$.

Com o advento da Lei Complementar n. 87, de 13 de setembro de 1996, por meio do seu artigo 20, buscou-se instituir um imposto sobre valor agregado em que se compensa o imposto incidente sobre as mercadorias adquiridas para revenda, serviços não compreendidos na competência dos Municípios prestados juntamente com o fornecimento das mercadorias, os bens instrumentais (uso e consumo), serviços de transporte inte- 
restadual e intermuncipal e de comunicação, os bens de produção, além dos componentes físicos (matéria-prima, embalagem e produtos intermediários). $\mathrm{O}$ parágrafo $5^{\circ}$ do artigo mencionado autoriza, por sua vez, o crédito de bens destinados ao ativo permanente na proporção de quarenta e oito avos por mês; atente-se que às microempresas nega-se esse direito, como já exposto.

Alterações nessa lei, que têm sido sucessivamente prorrogadas, restringem, nas operações e prestações de serviço no mercado interno, os créditos de energia elétrica à utilizada no processo de industrialização, os decorrentes de serviços de comunicação à produção de serviços dessa natureza, bem como adiado o exercício do direito de crédito aos bens de uso e consumo (atualmente para $1^{\circ}$ de janeiro de 2020). De qualquer forma, por extrapolar os limites do presente trabalho, abstém-se de analisar as especificidades e as repercussões dessas limitações de crédito.

Relativamente à compensação do ICMS, José Eduardo Soares de Melo (2004), após analisar os aspectos da hipótese de incidência desse imposto e a sistemática da não cumulatividade, conclui não se tratar de faculdade do sujeito passivo, mas obrigação dele decorrente de disposição constitucional que não pode ser restringida pela Lei Complementar (como ocorre, segundo o descrito no parágrafo precedente). Ele vai mais além e afirma que constitui dever da Autoridade Fazendária consentir e até exigir que se faça o crédito. (MELO, 2004, p. 113)

Ricardo Lobo Torres (2005, p. 288) considera que a não cumulatividade consubstancia uma expressão do princípio da capacidade contributiva, que veicula o valor justiça, em particular a justiça distributiva, denominada justiça fiscal que preconiza "[...] a adjudicação de parcelas da riqueza nacional a indivíduos concretos".

Reconhece esse autor a existência de impossibilidades fáticas e de inconveniência de política fiscal que deixam ao legislador certa margem de liberdade para não captar a efetiva capacidade contributiva do contribuinte. (TORRES, 2005, 309)

Dentro desse quadro, identifica limitações constitucionais: quantitativas, protetoras contra o excesso de tributação ou ao mínimo necessário à sobrevivência digna; qualitativas, que garantem o contribuinte contra as 
discriminações arbitrárias e os privilégios odiosos concedidos a terceiros. (TORRES, 2005, p. 304)

\section{O Simples Nacional e a Substituição Tributária Progressiva}

Com o objetivo de situar o tema da substituição tributária progressiva, também denominada pela "substituição tributária constitucional" ou "substituição tributária para frente", faz-se necessário analisar as diferentes formas de substituição tributária.

Observa José Eduardo Soares de Melo que, na lei tributária, elege-se a pessoa vinculada à realização do fato gerador do tributo, em especial a sua "materialidade" (segundo a terminologia do autor), que se traduz em índice de capacidade contributiva (MELO, 2004, p. 171) para ser o sujeito passivo. Em geral é o próprio contribuinte.

A CRFB, relativamente ao ICMS, indica como contribuintes: as pessoas que pratiquem operações relativas à circulação de mercadorias; prestadores de serviços de transporte interestadual e intermunicipal; prestadores de serviço de comunicação; bem como importadores de bens e mercadorias.

O texto normativo pode estabelecer responsabilidade pessoal, subsidiária ou solidária, segundo o Código Tributário Nacional. Diz-se solidária a responsabilidade se mais de uma pessoa integrar o pólo passivo da relação tributária, permanecendo todos eles responsáveis pelo pagamento da dívida.

A subsidiária ocorre se o terceiro for responsável pelo pagamento da dívida somente se constatada a impossibilidade de pagamento do tributo pelo devedor originário. Embora o artigo 134 do Código Tributário Nacional autorize a interpretação de que o terceiro assume a responsabilidade, como punição, em caso de omissão ou ação que der causa, tornando-se responsável solidário, junto com o contribuinte.

O responsável pessoal que pode ser eleito, pela lei tributária, para sujeito passivo, diferencia-se do contribuinte por ser necessariamente um sujeito qualquer: que não tenha praticado o evento descrito no fato gera- 
dor; e que disponha de meios para ressarcir-se do tributo pago por conta de fato praticado por outrem. (FERRAGUT, 2007, p. 11)

No ICMS, verifica-se a substituição pessoal regressiva, bem como a progressiva que se analisa a seguir.

Na substituição dita regressiva, a lei atribui a responsabilidade ao adquirente de uma determinada mercadoria por razões de praticidade ou pela circunstância de o real contribuinte não manter organização adequada de seus negócios. Isso caracteriza o fenômeno do diferimento em que ocorre a postergação da exigência tributária para momento posterior do ciclo mercantil. (MELO, 2004, p. 190)

Na substituição progressiva, o legislador indica uma pessoa responsável pelo recolhimento do tributo concernente a operação que provavelmente deverá ser realizada, no futuro, por outros contribuintes, segundo o disposto no parágrafo $7^{\circ}$, do artigo 150 da CRFB, introduzido pela EC n. 3, de 17 de março de 1993.

Regina Helena Costa (2009, p. 208) destaca que, embora conhecida no direito brasileiro, tal preceito inovou criar o fato gerador presumido, bem como uma garantia de reembolso quando o fato não tiver se realizado.

Em seguida, essa autora ensina que se trata de hipótese de tributação por fato futuro que ofende o princípio da capacidade contributiva, sobrepondo-se ao argumento de praticidade que se reconhece ao instituto da responsabilidade pessoal.

Contudo, o Supremo Tribunal Federal, ratificando sua posição no julgamento da Ação Direta de Inconstitucionalidade n. 1.851-4, considera a substituição progressiva uma expediente de política fiscal para assegurar o recolhimento do tributo. Elucida essa posição o voto do Ministro Ilmar Galvão:

[...] as realidades legislativas conduzem a que o jurista tributário não tenha, às vezes, outro remédio senão ser pragmático. Além da finalidade arrecadatória, permite o instituto seja alcançada maior justiça fiscal, pela distribuição equitativa da carga tributária que o sistema propicia, ao evitar a sonegação. (SUPREMO TRIBUNAL FEDERAL, 2002) 
Nesse julgamento no pleno do Supremo Tribunal Federal, Marco Aurélio de Mello fez a seguinte advertência:

[...] dificilmente teremos uma hipótese em que o valor presumido ficará aquém daquele resultante do fato gerador. Assusta-me, sobremaneira, o enriquecimento sem causa, considerado esse embate contribuinte - Estado. Assusta-me, sobremaneira, o risco de olvidarem-se os parâmetros constitucionais de um tributo. Assusta-me até mesmo a jurisprudência que se vem formando no tocante à relação tributária, nesta Corte, dia após dia, desequilibrando-se o embate que a Carta da República visa equilibrar. (SUPREMO TRIBUNAL FEDERAL, 2002)

Carlos Mário Velloso previne em vista da negação da restituição do excesso do ICMS recolhido em razão da base de cálculo efetivamente praticada no fato gerador presumido ser inferior à fixada pela disposição normativa da substituição tributária:

[...] o Fisco poderá fixar na pauta de valores, para o fim de ser recolhido o I.C.M.S., valor superior ao de mercado, valor superior ao preço pelo qual será o bem vendido. Não obtido, depois, o preço da pauta de valores, terá o poder público se locupletado ilicitamente, terá havido enriquecimento ilícito, o que a teoria geral do direito repele, o que o senso comum dos homens não admite. (SUPREMO TRIBUNAL FEDERAL, 2002)

Ainda que o Supremo Tribunal Federal tenha decidido em prol da substituição tributária, bem como se verificado os entendimentos diversos já destacados, permanece a controvérsia na doutrina ${ }^{5}$.

A controvérsia na doutrina sobre substituição tributário progressiva, no fundo, ainda resulta da concepção que se tem do surgimento da obrigação tributária principal, segundo o disposto no CTN. Elegendo três autores influentes e difundidos, Paulo de Barros Carvalho, Sacha Calmon Navarro Coelho e Ricardo Lobo Torres, em vista dos limites do presente

5 Neste sentido, ver o estudo efetuado por Pires (2006). 
trabalho, verifica-se o seguinte, o que leva a entendimentos que dão suporte aos votos no Supremo Tribunal Federal referidos.

Paulo de Barros Carvalho entende que a obrigação tributária decorre do fato típico na hipótese tributária, prevista em lei, e significa a

[...] descrição normativa de um evento que, concretizado no nível das realidades materiais e relatado no antecedente da norma individual e concreta, fará irromper o vínculo abstrato que o legislador estipulou na consequência. (CARVALHO, 2003, p. 244)

Sacha Calmon Navarro Coelho (2002, p. 615), com base em Kelsen, defende que a ocorrência do fato gerador produz a obrigação tributária, segundo o ocorre no Direito Privado, por exemplo, o "pagamento de alimentos" no campo do Direito de Família.

Ricardo Lobo Torres distancia-se da teoria geral das obrigações que, segundo os anteriores, aplica ao Direito Tributário e ao Direito Privado os mesmos princípios que naquele determinam as obrigações. Em contrapartida, considera-se que, embora a obrigação decorra de uma situação de fato ou jurídica (observe-se não algo que tenha necessariamente ocorrido) continua a ser ex lege. Assim isso deve ser complementado com o poder de administrar e julgar as controvérsias resultantes da aplicação da lei, devendo-se buscar o seu fundamento na ideia de justiça e nos princípios constitucionais dela decorrentes (capacidade contributiva, custo/ benefício e solidariedade social) e os relacionando com a problemática das conexões entre receita e gastos públicos. Enfim é " [...] rigidamente controlada pelas garantias dos direitos e pelo sistema de princípios da segurança jurídica.” (TORRES, 2003, p. 209)

Verifica-se que as abordagens de Paulo de Barros Carvalho e Sacha Calmon Navarro Coelho consideram inconstitucional a substituição tributária progressiva, em vista de sua concepção da obrigação tributária, o que, por si só, afastaria o problema desse estudo. Assim se prossegue considerando a concepção de Ricardo Lobo Torres sobre a obrigação tributária.

Analisadas as formas de substituição tributária, em especial o julgamento do Supremo Tribunal Federal que considerou constitucional a 
substituição tributária progressiva, passa-se a analisar a "opção" pelo regime simplificado ou especial de recolhimento de tributos.

\section{A “Opção" pelo Regime Tributário Especial ou Simplificado pelas Microempresas e Empresas de Pequeno Porte}

Analisa-se a seguir o regime especial ou simplificado pelas MEs e as EPPs, as obrigações tributárias acessórias a que estão sujeitas as empresas não optantes pelo Simples Nacional, em particular as companhias de capital aberto, o regime de fixação de preços e a proteção à opção pelo Simples Nacional.

O dispositivo constitucional que atribui a competência à União para instituir o Simples Nacional dispõe ser tal regime "opcional" para a microempresa e empresa de pequeno porte (inciso I do parágrafo único do artigo nacional, alínea "d”), segundo exposto anteriomente.

Embora a "opção" pelo Simples Nacional devesse reduzir a tributação no ICMS, ao contrário, veda qualquer crédito, inclusive nas importações, segundo já exposto. Além disso, mantém as "optantes" sujeitas à substituição tributária (artigo 13, inciso XIII, alínea "a” da LC n. 123/06), criando uma tributação mais onerosa do que a calculada sobre a receita bruta (artigo 18 da LC n. 123/06).

Ao referir "opção" a lei pressupõe que as MEs e as EPPs façam cálculos para decidir sobre a conveniência de "optar" pelo Simples Nacional, para dizer o menos, trata-se de mera formalidade, visto que o cumprimento das obrigações tributárias é mais complexo do mundo, como já destacado, sendo que as ME e as EPP “optantes" preferem suportar mais tributo pelo Simples Nacional segundo apuração pelo Simples Nacional, agravado pelo fato de serem as "substituídas tributárias", do que se sujeitarem às complexas apurações e obrigações tributárias acessórias, bem como os controles dos tributos.

Nas Ciências Contábeis, denominam-se "custos de conformidade" a aplicação de recursos para as empresas, no caso pesquisado as Companhias de Capital Aberto, adaptar-se às disposições normativas. Aldo 
Vincenzo Bertolucci (2001) arrola as ações que implicam os custos monetários diretos para uma empresa cumprir suas obrigações tributárias acessórias no Brasil para apurar tributos sujeitos ao lançamento por homologação no Brasil:

a) Impostos sobre vendas que as empresas tem que calcular, registrar, informar à administração tributária e pagar.

b) Cálculo da renda tributável observando que os conceitos de lucro da lei societária são diferentes da legislação tributária, fazendo os registros e ajustes definidos pela legislação, preenchendo declarações, controlando vencimento das obrigações e realizando seus pagamentos.

c) Retenção de impostos como contribuinte substituto quando assim definido pela legislação e sua entrega ao Fisco;

d) Recolhimento de contribuições previdenciárias e de imposto de renda na fonte por conta de seus funcionários.

e) Controle de preços de transferência nas transações com empresas ligadas dentro dos padrões estabelecidos pelas normas dos países envolvidos.

f) Arquivo e guarda de documentos por prazos superiores aos que seriam necessários para o negócio, para cumprir os múltiplos prazos definidos pela legislação tributária.

g) Manutenção de advogados dedicados ao contencioso tributário da empresa.

h) Processamento de dados com geração de informações tributárias rotineiras, geração de arquivos a serem conservados, alterações decorrentes de mudanças na legislação, relatórios especiais decorrentes de intimações fiscais.

i) Redação de normas internas relativas à tributação e a procedimentos necessários ao atendimento de determinações tributárias.

j) Registros da empresa e seus estabelecimentos nos fiscos federal, estadual e municipal.

k) Contratação de assessores tributários - advogados, economistas, contadores - para discutir, executar e controlar aspectos da tributação. 
1) Treinamento do pessoal interno para a realização de tarefas relativas a impostos.

m) Compra de livros, revistas e jornais especializados.

n) Tempo dedicado pelo Conselho de Administração, Conselho Fiscal, Diretoria, Controladoria, Jurídico, Compras, Vendas, Produção, Logística, dentre outros à discussão de temas tributários.

o) De forma um pouco diferente, a participação de funcionários da empresa em grupos de trabalho discutindo propostas para o aperfeiçoamento da legislação tributária, também pode ser classificada como Custo de conformidade. (BERTOLUCCI, 2001, p. 16)

Em nossa dissertação de mestrado (PUGLIESI, 1993, p. 34-35), em que foi orientador o Ministro Eros Roberto Grau, destacou-se, com base em Galbraith (1989) e Offe (1989), que, nas empresas do porte das analisadas por Bertolucci, o preço representa uma das forças sujeitas à influência da empresa, além do consumidor e do governo serem incitados para desejarem o que ela produz. Para isso elas dispõem de grande quantidade de recursos para instruir, controlar, treinar e supervisionar o processo de trabalho.

As ME e EPP, inversamente, têm o poder de atuar no mercado dentro de limites estreitos, o que as obriga ajustar a sua atividade ao que não é possível controlar. Dessa forma dependem do dinheiro disponível e da decisão dos consumidores para entrar do mercado, expandir ou contrair suas atividades ou sair do mercado; permanecendo fixos os gastos destinados a apurar e recolher os tributos. Gastos estes que o Simples Nacional ameniza ao determinar que os principais tributos devem ser recolhidos em guia única.

Dessa forma verifica-se que, embora o artigo 146, inciso III, alínea "d" da CRFB e parágrafo primeiro deste artigo constituam uma garantia ao tratamento diferenciado e favorecido para as ME e EPP (efetuado por meio do Simples Nacional) em razão do princípio impositivo que se deve promover o tratamento favorecido para as empresas de pequeno porte (artigo 170, inciso IX da CRFB), inexiste esta liberdade escolha quando o Estado institui um tributo que inviabiliza o exercício desta garantia. 
Verifica-se que a ME ou a EPP é não livre para optar, em vista dessa sua incapacidade decorrer da atividade legislativa do próprio Estado ${ }^{6}$.

Alexy considera que a inobservância de norma constitucional permissiva (a exemplo da garantidora da opção pelo tratamento simplificado para a apuração de tributos) ocorre ao se verificar uma violação pelo legislador da norma que proíbe inviabilizar o direito do contribuinte de optar por um tratamento que lhe mais favorável, a exemplo do verificado ao extrapolar sua competência para instituir a substituição tributária (artigo 150, parágrafo 7 da CRFB). Assim uma "liberdade não protegida" (veiculada por normas constitucionais que permitem fazer algo ou abster de fazê-lo) torna inconstitucionais as normas que ordenam ou proíbem algo que uma norma de direito fundamental permite fazer ou deixar de fazer, mas não se restringe a isso e complementa:

Ela (a proteção constitucional da "liberdade") é constituída por um feixe de direitos a algo e também por normas objetivas que garantem ao titular do direito fundamental a possibilidade de realizar a ação permitida. Se uma liberdade está associada a um tal direito e/ ou norma, então, ela é uma liberdade protegida. (ALEXY, 2011, p. 230-233)

Logo a instituição da substituição tributária de tributo, como o ICMS, quando o substituído enquadra-se no Simples Nacional, inviabiliza a opção por este regime de apuração simplificado de tributos, verificando-se a inconstitucionalidade da lei instituidora da substituição tributária, quando a ME ou EPP figura como substituída.

Irrelevante dizer que a CRFB não garante à ME ou à EPP o tratamento privilegiado quanto ao cumprimento da obrigação tributária, uma vez que neste caso se trata de apuração conjunta da obrigação dos tributos já mencionados, o que, inclusive, se destina a viabilizar e facilitar o cumprimento da obrigação tributária de todos os tributos a que se refere o Simples Nacional, revelando-se muito mais eficazes que a substituição tributária em função dos mecanismos para o cumprimento e controle de arrecadação deste, restando inaplicável o argumento para facilitar a ação

6 Neste sentido, ver Oppenheim (1986, p. 710-711). 
fiscalizadora do Estado do Ministro do STF, Ilmar Galvão por até inexistir a garantia à apuração simplificada de tributos à época do julgamento.

Por último, porém não menos importante, verifica-se, segundo a Ricardo Lobo Torres, um privilégio odioso para as empresas que conseguem impor sua política de preços ao mercado e recuperar custos (em especial da substituição tributária, a exemplo dos grandes supermercados, entre eles companhias de capital aberto), poder que não se verifica para as ME e EPP. Ademais ignora-se o princípio da vedação do excesso uma vez que ameaça a fonte da riqueza. (TORRES, 2003, p. 304-305)

\section{Conclusões}

Inicialmente analisou-se a disciplina do Simples Nacional, constatou-se que a experiência que a disciplina do Simples Nacional incrementa o rigor no controle da arrecadação, superior ao da reservada aos contribuintes "não optantes" do Simples Nacional, tendo se demonstrado que, ao invés de ser uma opção o microempresário e o empresário de pequeno porte vê-se forçado a optar pelo Simples Nacional, dada a complexidade da legislação tributária e os seus controles.

Em seguida, analisou-se a evolução do ICMS desde a instituição do ICM por meio da EC n. 18/65 à Constituição de 1946, bem como a funcionamento da não cumulatividade a ele relativa, efetuada por meio do crédito do tributo como expressão do princípio da capacidade contributiva. Considerou-se também a restrição ao direito de crédito para as empresas que apuram tributos no regime Simples Nacional.

Posteriormente, arrolou-se e analisou-se as formas de substituição tributária existentes no ordenamento jurídico, em especial a substituição tributária progressiva, bem como do acórdão do Supremo Tribunal Federal da Ação Direta de Inconstitucionalidade n. 1851-4. Verificou-se que, mesmo após esta decisão do Supremo Tribunal Federal, intérprete legítimo e máximo da CRFB, permanece a controvérsia na doutrina sobre a constitucionalidade da substituição tributária progressiva.

Por fim, estudou-se a disciplina da "opção" pelo Simples Nacional, os procedimentos para observância da legislação tributária pelas empresas 
não enquadráveis no Simples Nacional, o regime de fixação de preços e a proteção constitucional à liberdade de opção pelo Simples e a substituição tributária, julgada constitucional pelo Supremo Tribunal Federal antes da EC n. 42/03 que autorizou a instituição do Simples Nacional por lei complementar.

Dessa forma, conclui-se pela incompatibilidade da competência para instituição da substituição tributária progressiva, conferida pelo artigo 146, inciso III, alínea "d" da CRFB (incluída pela EC n. 3/93), quando a ME e a EPP enquadra-se no Simples Nacional, cuja instituição decorre da competência do artigo 150, parágrafo 7 da CRFB (acrescentada pela EC n. 42/03).

\section{Referências}

ALEXY, Robert. Teoria dos direitos fundamentais. São Paulo: Malheiros, 2011.

BALTHAZAR, Ubaldo Cesar. História do tributo no Brasil. Florianópolis: Fundação Boiteux, 2007.

. A gênese do imposto sobre o valor agregado. Florianópolis:

Revista Sequência, n. 56, p. 245-246, jun. 2008.

BECKER, Alfredo Augusto. Teoria geral do direito tributário. 3. ed. São Paulo: Lejus, 1998.

BERTOLUCCI, Aldo Vincenzo. Uma Contribuição da Incidência dos Custos de Conformidade às Leis e Disposições Tributárias: um panorama mundial e pesquisa dos companhias de capital aberto no Brasil. São Paulo, Dissertação de Mestrado: Faculdade de Economia e Administração da Universidade de São Paulo, 2001. Disponível em: <http://www. teses.usp.br/teses/disponiveis/12/12136/tde-18042007-145400/pt-br. php>. Acesso em: 30 set. 2011.

. Supremo Tribunal Federal. ADIN/AL n. 1851-4. Relator: Ministro Ilmar Galvão. Julgamento em: 8/5/2002, publicado no DJ de 22/11/2002. Disponível em: <http://redir.stf.jus.br/paginadorpub/paginador.jsp?docTP=AC\&docID=266781>. Acesso em: $1^{\circ}$ nov. 2011. 
CANOTILHO, José Joaquim Gomes. Direito constitucional, 5. ed. Totalmente refundida e aumentada. Coimbra: Almedina, 1991.

CARVALHO, Paulo de Barros. Curso de direito tributário. São Paulo: Saraiva, 2003.

COELHO, Sacha Calmon Navarro. Curso de direito tributário: comentários à Constituição e ao Código Tributário Nacional, artigo por artigo. Rio de Janeiro: Forense, 2002.

COSTA, Alcides Jorge. ICM na Constituição e na Lei Complementar. São Paulo: Resenha Tributária, 1978.

COSTA, Regina Helena. Curso de direito tributário: Constituição e Código Tributário Nacional. São Paulo: Saraiva, 2009.

FABRETTI, Láudio Camargo. Simples nacional: Estatuto Nacional das Microempresas - ME e das Empresas de Pequeno Porte - EPP: Regime Tributário Simplificado, Lei Complementar n. 123, de 14 de dezembro de 2006, Lei Complementar n. 124, de 14 de agosto de 2007. São Paulo: Atlas, 2007.

FERRAGUT, Maria Rita. Responsabilidade Tributária: Conceitos fundamentais. In: FERRAGUT, Maria Rita; NEDER, Marcus Vinícius. Responsabilidade tributária. São Paulo: Dialética, 2007.

GALBRAITH, John Kenneth. A Economia em perspectiva: uma história crítica. São Paulo: Editora Pioneira, 1989.

GRAU, Eros Roberto. A ordem econômica na constituição de 1988: interpretação e crítica). 12. ed. Revista e aumentada. São Paulo: Malheiros, 2007.

GRECO, Marco Aurélio. Planejamento tributário. São Paulo: Dialética, 2004.

MACIEL, Andréia Marques; VICENTIM, Ana Maria; VICENTIM, Cássia Regina; MARINO JR., João. Planejamento tributário para micro e pequenas empresas. Disponível em: $<$ http://www.planejamentotributario.ufc.br/artigo_Planej_Tribt_Micro_e_Peq_Empresa.pdf $>$. Acesso em: 25 ago. 2007. 
MELO, José Eduardo Soares de. A não cumulatividade tributária: ICMS, IPI, ISS, PIS e COFINS. São Paulo: Dialética, 2004.

. ICMS: teoria e prática. São Paulo: Dialética, 2010.

OFFE, Claus. Capitalismo desorganizado. São Paulo: Brasiliense, 1989.

OPPENHEIM, Felix E. "Liberdade". In: Dicionário de política, por Norberto Bobbio, Nicola Matteucci e Gianfranco Pasquino. Brasília, Editora Universidade de Brasília, 1986, p. 710-711.

PIRES, Klauber Cristofen. Substituição tributária progressiva: jurisprudência e teoria [2011]. Disponível em: $<$ http://www.buscalegis.ufsc. br/revistas/files/anexos/21336-21337-1-PB.pdf > . Acesso em: $1^{\circ}$ nov. 2011.

PUGLIESI, Fabio. Contribuição ao estudo do controle de preços. São Paulo, Dissertação (Mestrado em Direito): Faculdade de Direito da Universidade de São Paulo. 1993.

PUGLIESI, Fabio; PIRES, Gisele Sotero Amorim. A aplicabilidade da criminologia crítica na tributação e o simples nacional. Rio de Janeiro: Juris Poiesis, ano 11, n. 11, 2008, p. 207-218.

THE WORLD BANK. Doing Business in Brazil, 2010. Disponível em: $<$ http://portugues.doingbusiness.org>. Acesso em: 9 nov. 2011.

TORRES, Ricardo Lobo. Curso de direito financeiro e tributário. Rio de Janeiro: Renovar, 2003.

. Tratado de direito constitucional financeiro e tributário:

valores e princípios constitucionais. Rio de Janeiro, Renovar, 2005.

ZAVARIZI, Indio Jorge. Política do direito tributário. Florianópolis:

Universidade Federal de Santa Catarina, (Tese apresentada como requisito para a obtenção do grau de doutor), mimeo, 1993. 